\title{
Visual Framing and News Media: An Analysis of Contemporary Research
}

\author{
*Huma Parveen \\ **Nayeem Showkat
}

\begin{abstract}
Visuals used in news have always had the audience enraptured. Their presence has been an added advantage for the comprehension of a story. The present study endeavours to explore the concept of visual framing in news media. Consulting an extensive literature regarding visual framing, the study attempts to understand how visuals work and how they have been used by news media to frame messages. The interplay of visual and verbal information and their effectiveness together in framing of news has been analysed. The idea of manipulation using images in the modern day environment as well as the visual gatekeeping process have also been discussed.
\end{abstract}

Key words: images, visuals, visual framing, news media, manipulation

\footnotetext{
*Assistant Professor, Department of Mass Communication, Aligarh Muslim University, Aligarh, UP, India. Email address: humaparveen97@gmail.com

**Research Scholar, Department of Mass Communication, Aligarh Muslim University, Aligarh, UP, India. Email: nmkhan620@gmail.com
} 


\section{Introduction}

News media channels are the carriers of news to the public. These media existed as early as the Renaissance period in Europe, and have evolved over time. The earliest form of news media that was primarily print, saw evolution and transformation into audio-visual mediums with the consequent advancement of technology. Pictures and images have been integral to news media throughout the phase and have been witnessing a continuously changing media environment. However, to this day, the significance of pictures in news remains insurmountable.

'Framing' has been a key concept in the study of mass communication. Its origins can be traced way back to the 1950s, when Gregory Bateson, in his essay titled 'A theory of play and fantasy; a report on theoretical aspects of the project for study of the role of paradoxes of abstraction in communication', talked about how the meaning of any communication is derived only through its context and the way in which the message is constructed (Vliegenthart, 2012).

Connecting the two ideas of visuals and framing, the present study endeavours to explore the concept of visual framing in news media. Consulting an extensive literature regarding visual framing, the study attempts to delve into the intricacies involved. The terms that have been used to refer to visuals include 'pictures, images, photographs and visuals'.

\section{The Power of Images}

"Ideally, and perhaps rather idealistically, the pictures are an 'invitation to pay attention"” (Sontag, 2003). Images hold significance as they remain uninhibited by linguistic and geographical barriers (Popp and Mendelson, 2010). Photographs are images that can be said to portray the reality very directly (Joffe, 2008).

The power of images makes them a mode to communicate meaning immediately. As Mirzoeff (1999) puts it, "It imposes meaning at one stroke without the need to analyze it". Images are one of the factors that are capable of evoking and stimulating emotional responses from the 
viewers. According to Perlmutter's (1998) typology that delineated the influence of visual images, "manifest content is thought to foster an emotional connection between the viewer and what is viewed".

Bucher \& Schumacher (2006) suggest that visuals are more easily understood, retained and retrieved from one's memory as compared to text. Gibson \& Zillmann (2000) argue that visual information excessively influences one's "impression and judgement" owing to its greater occupancy of the mind as against textual information.

People react with more alarmed responses if they are exposed to visual images of kidnapping, as against those who were exposed merely text based information. When a viewer is 'moved' along emotional pathways, visual images evoke stronger responses as their content is more vivid. (Iyer and Oldmeadow, 2006)

Images used in news are believed to stimulate public's emotions and lead to outcry better than any other mode of expression (Sharkey, 1993). Indeed, there exist instances aplenty that vouch for the power of images. They suggest that no matter how articulate the verbal account of an event, it can never be beaten by its depiction through pictures (Zillmann, Gibson and Sargent, 1999).

Technology has made images omnipresent, especially with digital camera equipped mobile devices. To add to that are the platforms allowing instant spread of images like Instagram, Vine, Twitter, Snapchat, along with television and YouTube. Therefore, an average citizen in developed countries is exposed to numerous images every day (Rosen 2005).

The world around is teeming with images and policy makers also agree to their clout (Campbell, 2007). The key people in the communications industry including the journalists, editors and publishers "produce and interpret images in order to engage people" (O’Neill and Boykoff, 2011) 
The pictures used in news carry immense potential. "News images seem to have the useful magic of causing consciousness of thinking and considering the articles of the media." They act as propellants for people to extend their thoughts towards other pertinent issues (Domke, et al., 2002).

Images are believed to enhance the beauty and liveliness of the layout, thus making the printed page or the newscast more eye-catching and attractive for the users (Rivers \& Matthews, 1988). Some images have also been argued to be symbols that have the capacity to develop the public interpretations of an event (Perlmutter and Wagner, 2004).

Emotionally charged photographs in news have been found to enhance the recall of a newspaper report (Wanta and Roark, 1993). A study conducted by David (1998) also noted that if a news report carried illustrations, it had a better recall value than the report that was non-illustrated, specifically in case of the illustrated news items being concrete entities rather than abstract ones.

As images create the feeling of "eye-witnessing", this makes them credible and trustworthy. Therefore, they are considered to be highly effective and "intrusive in circumstances that only allow low involvement perception" (Rodriguez \& Dimitrova, 2011).

During the early days after the birth of printing press, words were the principal vehicles of conveying ideas. But, with the passage of time, the significance of visuals changed drastically with the advent of visual-based media like television, computers, and internet. These media ushered in an era where visuals and their perception by the public had transformed (Lester, 2005). Indeed, photographs have become mirrors to the reality of a situation, and they are able to develop a close connect with the readers by drawing emotional responses (King \& Lester, 2005; Lester, 2005). 
Television news stories were found to be better remembered by the viewers through visuals, particularly when the visuals were more personalised by featuring uncommon places and human figures (Graber, 1990).

Studies also suggest that audiences connect more easily with the content expressed in terms of photographs, while merely textual information does not seem as familiar (Gefter, 2006). Very often, readers/viewers only focus on photographs, while not even reading the story accompanied with it (Miller, 1975).

Various studies suggest that images used in news play an important role in assessing sociopolitical ideas and experiences (Fahmy, Cho, Wanta and Song, 2006). A study on the news coverage of Vietnam conflict found that the photographs interact with the preconceived ideas of individuals and accordingly mould their perception and judgments (Domke, Perlmutter, and Spratt, 2002).

Ali \& Mahmood (2013) argue that the images published in newspapers reflect the reality more closely than textual information. Photographs are the first things to grab a reader's attention in a newspaper.

In cases of disasters and suffering, pictures convey an immediate sense of impact and implication. Jackson (2011) examined three 'interlocking narratives of beauty, ruin, fraternity' in a study on flood in Paris. The research took into account how people interpreted the scale of destruction through the photographs of the city drowned in water.

Lester \& Ross (2003) further argued in their book about news photographs that "They do not become iconic symbols of a particular event. Rather they serve as source of information that audience members can incorporate into their understanding of story".

However, it cannot be presumed that all pictures lure the readers to the same extent. According to Garcia and Stark (1991), in essence, all pictures are noticeable and attract the reader's eye 
for a moment, yet it is improbable that they all have the same ability to tweak interest about the accompanying story and lure the reader into the text. Indeed, their initial findings also highlight the differences in attention with the variation in content. It was found that "Image categories such as news, features, mug shots, recognizable versus unfamiliar newsmakers, people with versus without particular expressions were largely inconsequential for attention, with only mug shots standing out as least worthy of attention." Though, the study could not establish the consequences for reading. Indeed, the responses given by news personnel are rather imprecise. They argue that the purpose of images is to support, instead of contradicting the central point of a report; or they are supposed to back the various "foci in a multifaceted report". Whether pictures promote reading of the text, yet remains to be proven through research studies. However, the 'pictures-foster-reading' connection has been considered as a 'truism' that stands acknowledged by the ubiquitous pictures in news media portraying human misery, widespread violence and destruction.

Though the prolific use of such images is many times criticised on ethical grounds by both the readers as well as journalists. Lester (1991) condemns the adage 'if it bleeds, it leads' as an unacceptable premise. Some researchers denounce the show of gore and violence through photographs to depict human suffering, considering that such display intrudes the victims' privacy (Gross, Katz, \& Ruby, 1988).

On the contrary, others have attested to the justification of such display, citing that they may not be enriching, but certainly 'instructive' (Husselbee \& Adams, 1996). Another research claims that the public is responsible for the pervasive use of images to signify terror, suggesting that "the American public has a morbid fascination with violence and tragedy, yet this same public accuses journalists of being insensitive and cynical and of exploiting victims of tragedy" (Brown, 1987). 


\section{Framing through Visuals}

Visual framing can be defined as the process of choosing certain aspects of a 'perceived reality' and emphasising them more than others through the mode of visual communication, thus increasing their salience and meaning. This visually promotes those specific 'attributions, interpretations, or evaluations' of the said issue or item described (Geise, 2017).

The constructs in the minds of news consumers are more directly activated and influenced by information targeted at them through visual frames, which highlight some components of issues over others (Rodgers, Kenix \& Thorson, 2007).

Visual framing is the representation of the visual elements present in an image and how these elements are related to each other within the image. These frames are a result of the selections made by creators and editors while image creation (Coleman, 2010; Hansen \& Machin, 2013).

Rebich-Hespanha et al. (2015) claim that visual elements and the representation of their interrelationships within an image is what constitutes visual framing. The choices made by creators of the image, ranging from selecting the subject, background, camera angle, and editing, ultimately create visual frames (Coleman, 2010; Hansen \& Machin, 2013). These choices, made either consciously or unintentionally, are moulded by the 'narratives and meta-narratives' reflecting similar discourses (McComas \& Shanahan, 1999).

Images seem to carry more significance than text as they frame messages "in a less obtrusive manner". They are accepted more readily by the viewers as reflecting the reality in that they are supposed to show things just as they actually are (Messaris and Abraham, 2001). Therefore, images have tremendous capacity to frame messages.

The mechanism of perceiving pictures does not allow much cognitive control. This makes visual framing quite appropriate for expression of ideas that would have encountered a resistance from the consumers, if conveyed through words (Messaris and Abraham, 2001). 
Moreover, pictures take much lesser time in processing as compared to text (Lester, 2005; Wedel \& Pieters, 2007). They are considered easier to perceive and understand, notwithstanding that fact that there may be certain hidden elements of the meaning that remain undisclosed. "The special qualities of visuals - their iconicity, their indexicality, and especially their syntactic implicitness - makes them very effective tools for framing and articulating ideological messages" (Messaris \& Abraham, 2001). Yet, they continue to hold significance as a more effective mode of communication than mere textual information (Kress \& van Leeuwen, 2006; Lester, 2005; Wedel \& Pieters, 2007).

According to Entman (1991), drawings, illustrations, photographs, photo-illustrations and other graphic devices are collectively referred to in this study as "visuals" or "images" that can be examined or evaluated for the frames they convey. Visuals, like text, can operate as framing devices insofar as they make use of various rhetorical tools - metaphors, depictions, symbols that purport to capture the essence of an issue or event graphically. Through the application of these devices, a salient idea becomes easier to understand and easier to remember than other ideas.

According to Tewksbury and Scheufele (2009) and Entman (2003), framing is the process of presenting certain topics in the news intentionally using certain words and pictures so as to highlight or promote a desired interpretation of the issue. Instead of inducing attitude changes, framing is primarily based on cognitive responses that show how audience interprets an issue (Tewksbury and Scheufele, 2009, p. 20).

\section{Analysing Visuals}

Fahmy, Kelly \& Kim (2007) say that "The visual reporting in newspapers is much more than a playlist provided by the wire services passed on to readers". The editors make decisions about 
providing the visual coverage of an event based on the news values complying with their discipline and target audience.

Schwalbe (2006) writes that visual framing is a process of continuous sorting. It involves a process of making a horde of decisions ranging from choosing the events to be covered, to the pictures to be taken, their overall presentation (camera angle, viewpoint, assumptions and biases, cropping, etc.), and their incorporation into the story. Further choices are made inside the newsroom as to which images to be finally included and how they are positioned on a particular page.

Some studies have relied on counting the salient visual frames in the coverage of an event. The images present in each frame are counted. The size and placement of the image also determines the relevance of an issue (Bulla and Borah, 2006).

According to Entman (1991), sizing is the 'essence' of visual framing. Wanta (1988) argues that articles with large size photographs lend a sense of more prominence to the readers, in comparison to those with smaller photographs. Thus, simply increasing the image size can actually lead to a story appearing more important over a short period of time.

The location of pictures within a publication is another important determinant of salience. Visual framing studies have often relied on examining the front page photos, coding them as dominant and non-dominant (see Fahmy, Kelly \& Kim, 2007; Geske \& Brown, 2008). Front page photographs receive more attention against those published on the inner pages of a newspaper, and are automatically more dominant (Kiousis, 2004). Further, on the front page, the photographs that appear 'above the fold' wield greater optical attraction (Geske \& Brown, 2008). 
Visual framing needs to be studied at various levels- "from denotation (description of photo content, organization into themes), to semiotic-stylistic resources employed by the photo, to its connotative meanings, and finally to the ideological message embedded in it" (Nurmis, 2017).

Analysis of visuals as 'stylistic-semiotic systems' deals with the "stylistic conventions and technical transformations" entailed in the entire process of visual representation (Rodriguez and Dimitrova, 2011). A close-up shot of an act of violence is more heart wrenching than a long shot (Fahmy, 2010). As per social distance theory propounded by Hall (1966) "the perceived social distance in photos creates a feeling of intimacy or distance” (Mullen, 1998). The perceived degree of intimacy is higher in close-up shots, while long shots convey a more contextual and distanced view on the subject matter (Mullen, 1998; Rodriguez \& Dimitrova, 2011).

A study conducted to analyse the social distance and point-of-view in wire photographs during and after the collapse of Taliban rule in Afghanistan found that there existed a difference between the portrayals of women during the two time periods. After the regime fell, the pictures depicted women as more socially intimate, lending a sense of their equality to the viewers (Fahmy, 2004).

This shaping of a message using technical elements such as the camera angles and distance of the subject from the camera builds frames that can influence viewers' perception about the subject and the situation (Jewitt and Oyama, 2001).

Another study by Borah (2009) examined the pictures used to depict two disasters (the Indian Ocean tsunami and the Hurricane Katrina) by two prominent US newspapers - The New York Times and The Washington Post. The results revealed that the newspapers chose closer shots in case of Indian Ocean tsunami in 2004. While showing victims of Hurricane Katrina in 2005, 
mostly longer shots were used, thus emphasising public distance. These studies indicate that visual frames are influenced by the compositional elements of images.

Therefore, visual framing can be said to progress through a series of steps: from the deputation of a photographer for a specific task by the photo editor, to the photographer's actual work on field, his/her own decisions about the composition, timing, camera angle, camera distance, exposure, size, and again back to the photo editor who would make selections from the throng of pieces available with him. Together, the photo editor, along with layout editors and news editors, decides where and how the image would be placed ultimately (Nurmis, 2017).

\section{Visual-Verbal/Text-Image Connection}

The non-verbal 'nonlinear and multidimensional' human experiences that are carried in an image, work together with text to form perceptible messages (Foss, 2005).

Framing is the interplay of textual and visual discourses. The visual elements in an image are juxtaposed in such a way that they promote a certain interpretation about the relationship existing between the entities shown. Thereby, it can be garnered that the text and image "frame one another in a mutual fashion with text highlighting certain elements of the imagery, and imagery drawing attention to particular aspects of the text" (Messaris and Abraham, 2001).

Grimes (1990) and Grimes and Dreschel (1996) investigated the misleading text-image combinations that lead to defamatory cues. It was found that while the visuals may not themselves be defamatory in nature, yet, the entire report may become defamatory by juxtaposing the subjects present in the image with negatively referential text.

Images are so powerful that their presence, and the absence as well, in a news report influences the interpretation of the story (Entman, 1993). Along with enhancing the learning experience, 
the meld of visual and verbal messages effects the readers' understanding of the issues represented (Coleman, 2010, p.242).

\section{Visual Primacy}

This blend of text and image also results in the impressions the news reports form on the minds of the readers. Gibson \& Zillmann (2000) maintain that photographs can altogether shift the readers' focus from what the text conveys to the direction of what the picture suggests.

If there arises a conflict between visuals and the text, it is likely for the viewers to take visual information as more reliable (Patterson, Churchill, Burger, \& Powell, 1992). A lot of previous research has proven this 'visual primacy' effect where pictures stand superior to text (Paivio \& Csapo, 1973).

It can be understood in light of 'cue summation' i.e. multiple cues across multiple channels. When visuals conjoin verbal messages, the pictures provide additional information, particularly in context of retrieval from memory (Paivio, 1971; Severin, 1967).

Ferguson (2001) writes that images require lesser effort being used in the working memory, making them powerful framing tools. This may activate peripheral processing, instead of central, leading to the audiences accepting the visual frame more readily. Barry (2005) says that though visual information enters the eye through cornea, yet it is the visual cortex where actual vision takes place. Thus, eyes are considered to be 'a direct extension of the brain into the environment' (Barry, 2005, p. 48). "The last and most sophisticated of our senses to evolve, our eyes send more data more quickly and efficiently through the nervous system than any other sense."

Images provide more immediate cues and evoke stronger emotions. Even history reveals that seeing came first, while use of language came later. The images displayed on pages, web sites, or any other screen are very often the first glimpse of any story, thereby making it easier to 
remember (Rogers and Thorson, 2000). Wischmann (1987) opines that pictures are "capable of not only obscuring issues but [also] of overwhelming facts" (p. 70).

As far as storage in the memory is concerned, there exists a qualitative difference in visual and verbal messages. The 'dual-code-theory' assumes that there should be differentiated encoding for the two (Kolers \& Brison, 1984; Kroll \& Potter, 1984; Paivio, 1971, 1986). The theory lays that textual and visual information form two different subsystems which are constantly interconnected. The information of both conjoin to achieve a cognitive effect. This helps understand the observation that "dual modal presentations of information pictorial juxtapositions with verbal messages can enhance the memory for and comprehension of verbal information" (Burgoon, 1985; Folger \& Woodall, 1982; Gunter, 1987; Stone, 1987).

\section{Manipulation through Visuals}

Rodriguez (2011) argues that text is likely to be more efficacious in explaining cause and effect relationships. It may be a bit difficult to identify frames in images unsupported by text, because "claims are less likely to be perceived in visual depictions of reality that stand alone (without text)". While the editors and photographers may feel they are making a visually syntactic appeal through the images they select, the viewers rather comprehend their meaning through the context and other related cues. They may not be conscious of the fact that the information being presented has been pre-selected omitting specific visual hints.

At the beginning, photography was being considered as a revolutionary medium that presented an exact eyewitness account, untainted by "subjectivity, memory lapses, or flights of fancy" (Goldberg, 1991, p. 19). At present, the ability of images to manipulate messages is well known. Yet, sophisticated observers are found to believe the camera's report, though unconsciously (Goldberg, 1991). 
The moment a photographer lifts the camera, he/she has to choose ranging from the lens to be used to the light settings, the camera distance from the subject to the shot composition. Elliot \& Lester (2003) claim that any decision made based on the above considerations will result in some or the other form of manipulation; but they add that this may not necessarily be negative. Sontag (2003) claims that photographs are not merely a mirror to whatever happened. Rather, they are a result of careful choices made by someone. Whatever is chosen to be excluded from a photograph also plays an important role in framing audiences' perceptions. She writes, "To photograph is to frame, and to frame is to exclude" (Sontag, 2003, p. 46). Entman (1993) avers that while frames draw attention to certain aspects of reality, they also divert attention from others.

War photography is an excellent example of such manipulation. In the first place, its purpose was to garner support for soldiers and glorify them. "To photograph was to compose (with living subjects, to pose), and the desire to arrange elements in the picture did not vanish because the subject was immobilized, or immobile" (Sontag, 2003).

Media plays a fundamental role in structuring visibility. Butler (2011) aptly describes this process of deliberate inclusion and exclusion. While discussing about the street scenes of protest, she writes, "Although the scene is surely and emphatically local, and those who are elsewhere have the sense that they are getting some direct access through the images and sounds they receive. That is true, but they do not know how the editing takes place, which scene conveys and travels, and which scenes remain obdurately outside the frame".

Therefore, which images find their way to the public through news media and how they are used, builds frames that evoke particular "emotional responses, moral evaluations and action recommendations" (Entman 1993: 52; see also Parry 2010). 
Moreover, images contain multi-layered meanings, while text is more clearly defined. Therefore, they depict multiple perspectives simultaneously, instead of objectively presenting the clear report of any event. In case of natural calamities, pictures may lead to creating a pseudo-reality (Faux II and Kim, 2006).

Photographers' choices are crucial as they make for the first step of visual framing. It all depends on what they choose to cover and what they choose to hide, that will create the ultimate impression. "A photograph of a smiling subject will frame a message in a different manner than a photograph of a crying one. The inclusion of others in the image, the apparent relationship between the subjects and the type of activity represented also can visually frame a message for a viewer." (Greenwood, 2012).

The subject, camera angle, lighting and frame are the decisions made by photographers. Whereas, afterwards, it is the editor's choice with respect to the context, position on the page and the accompanying caption that will further effect the visual framing (Moriarty \& Popovich, 1991; Rodgers \& Thorson, 2000; Kruif, 2009).

According to Messaris and Abraham (2001), since images reveal the reality more closely, they can be easily understood without the knowledge of any grammar. At the same time, this makes them an effective tool to mislead viewers as they can also be artificially constructed.

Peirce (1868) used the idea of 'indexicality' to indicate true-to-life qualities of photographs, which gives them an edge in being closer to reality. Messaris and Abraham (2001) contend that because of this feature, photographs are accepted and believed by the viewers without questioning. However, the manipulation of viewers through photographic practices is well known.

Grundberg (1990) quotes The New York Times photography critic Andy Grundberg, "In the future, readers of newspapers and magazines will probably view news pictures more as 
illustrations than as reportage, since they can no longer distinguish between a genuine image and one that has been manipulated".

Many a times, manipulation takes place at the editing stage. It can be a simple colour correction, or a derogatory manipulation to alter the overall impression of meaning implied. The manipulations can take place at the hands of the photographer at ground zero or on the desktop computers inside the newsrooms (Quinn and Spence, 2004). Various software such as Photoshop offer a huge scope of digital manipulation which "gives rise to a 'slippery slope' ethical decision making” (Harris, 1991).

\section{Visual Gatekeeping}

Like any other news item, photographs also have to pass through a rigorous selection process wherein the editor selects a few from numerous 'potentially storytelling photographs' (i.e., Fahmy et al., 2007; Fahmy 2005).

Newspaper editors' choices are driven by the market size, requirements of the audience, traditions. The shifting role of copy editors and designers, as well as the national trends also influence their decisions (Keith, 2015; Wanta and Roark, 1993).

The gatekeepers of visuals, or the photo-editors consider the conventional news values like personalisation, elite status and proximity, while also taking into account the aesthetic values like overall composition, clarity, colour and movement. Though the primary professional principles of both news and photo editors were same, yet the 'visual elite' (photo editors) emphasised more on aesthetic value (Seelig, 2005).

However, there are also other factors at play ranging from "audience sensitivities and good taste to privacy and newsworthiness" (Kratzer and Kratzer 2003; O’Brien1993). Sometimes, the editorial choices of photojournalists and photo editors create a visual syntax (Rodriguez and Dimitrova 2011). Photo-editors are often guided by the 'breakfast test' in journalism. "It 
identifies our habitual skittishness about publishing language or images that would make readers spew into their cornflakes as they read the morning paper. Photograph of a dead body? Racy language? Graphic description? An editor will want to know whether they pass the breakfast test." (McIntyre, 2010)

Potter and Smith (2000) observe a violent act appears more graphic in a close shot than a long shot of the same act. The degree of physical alteration of the victim also matters with the photo editors, for example, a victim lying in a pool of blood, the eyes wide open instead of shut.

\section{Paucity of Research}

History is witness to the fact that visuals have been appended great importance by various news media while covering significant stories. However, there exists a lack of systematic research on the visual elements of news, while most of the studies have focussed on the textual aspect (Domke, Perlmutter, \& Spratt, 2002; Graber, 1989, 1990; Matthes, 2009).

Though framing is being widely used in research, yet it has rather been confined to analysis of texts (Berger, 1991). This is an unfavourable trend as visuals carry a lot of weight. While studying framing theory, it is imperative to incorporate the role played by visual elements as they bear a strong influence on the written content (Matthes, 2009).

The frames that emerge from pictures supported by text as against those pictures which are stand-alone, have not received much attention of researchers yet (Bell, 2001). The importance of images cannot be overlooked as they have features that are capable of enhancing or mitigating their effects (Messaris \& Abraham, 2001, p. 215). At times, they are powerful enough to even supersede the message in the textual part (Wischmann, 1987).

The scarcity of research on visual framing offers new avenues for "theory building and future research" (Coleman, 2010). 


\section{Conclusion}

Visual framing is the deliberate presentation of visual elements in a picture so as to emphasise a certain meaning. The relationship among the various elements and the context together create a specific meaning to be comprehended by the viewer. Indeed, while there can be different ways of interpretation of an image, its framing prods the onlooker to see things from a particular 'pre-decided' point-of-view. The text remains consequential as it works in tandem with the visuals. Yet, they work together in a mutual fashion, with one adding to the meaning of the other. However, in case of a discrepancy between the meanings portrayed by the two, it is often the visuals that win over.

Visuals offer a greater chance of manipulation as well. Their strong influence in conveying meanings makes them very sensitive tools, since they can also be used to mislead the audience. In the present age of advanced technology, photographic manipulation has become very easy and rampant. The visual gatekeeping process currently being practiced needs to be refined further to address the contemporaneous realities of visual manipulation.

Visual framing continues to be a phenomenon that demands more attention from the researchers. Going by the wide literature review, it is apparent that visual framing has a farreaching applicability. It can contribute to the existing theory in a meaningful way, helping deconstruct the layers of meanings in visual communication, opening up new vistas of understanding.

\section{References}

1. Ali, A., \& Mahmood, S. (2013). Photojournalism and disaster: Case study of visual coverage of flood 2010 in national newspapers. Academic Journal of Interdisciplinary Studies, 2(9), 168-176. 
2. Barry, A. M. (2005). Perception theory. In K. Smith, S. Moriarty, G. Barbatsis, \& K. Kenney (Eds.), Handbook of visual communication (pp. 45-62). Mahwah, NJ: Erlbaum.

3. Bell, P. (2001). Content analysis of visual images. In T. Leeuwen \& C. Jewitt (Eds.), Handbook of visual analysis. Thousand Oaks, CA: Sage Publications.

4. Berger, A. A. (1991). Media research techniques. Newbury Park, CA: Sage Publications.

5. Bucher, H-J., \& Schumacher, P. (2006). The relevance of attention for selecting news content: An eye-tracking study on attention patterns in the reception of print and online media. Communications: The European Journal of Communication Research, 31(3), $347-368$.

6. Bulla, D., \& Borah, P. (2006, June). The visual framing of the Indian Ocean tsunami and hurricane Katrina: A comparison of newspaper coverage in three countries. Paper presented at the annual meeting of the International Communication Association, Dresden, Germany.

7. Campbell, D. (2007). Geopolitics and visuality: sighting the Darfur conflict. Political Geography, 26, 357-382.

8. Coleman, R. (2010). Framing the pictures in our heads: Exploring the framing and agenda setting effects of visual images. In P. D’Angelo \& J. A. Kuypers (Eds.), Doing framing analysis: Empirical and theoretical perspectives (pp. 233-261). New York, NY: Routledge. 
9. David, P. (1998). News concreteness and visual-verbal association: Do news pictures narrow the recall gap between concrete and abstract news? Human Communication Research, 25(2), 180-201.

10. Domke, D., Perlmutter, D., \& Spratt, M. (2002). The prime of our times? An examination of the power of visual images. Journalism, 3(2), 131-159.

11. Elliot, D., \& Lester, P. (2003, August). Manipulation: The word we love to hate. News Photographer, 12-14.

12. Entman, R. (1993). Framing: Toward clarification of a fractured paradigm. Journal of Communication, 43(4), 51-58.

13. Entman, R. M. (1991). Framing U.S. Coverage of International News: Contrasts in Narratives of the KAL and Iran Air Incidents. Journal of Communication, 41(4), 6-27.

14. Entman, R. M. (2003). Cascading activation: Contesting the White House's frame after 9/11. Political Communication, 20(4), 415-432.

15. Fahmy, S. (2005). Emerging alternatives or traditional news gates: Which news sources were used to picture the $9 / 11$ attack \& the Afghan War? Gazette: International Communication Gazette, 67(5), 383-400.

16. Fahmy, S. (2010). Contrasting Visual Frames of our Times: A Framing Analysis of English and Arabic-language Press Coverage of War and Terrorism. International Communication Gazette, 72(8), 695-717.

17. Fahmy, S., Cho, S., Wanta, W., \& Song, Y. (2006). Visual agenda-setting after 9/11: Individuals' emotions, image recall, and concern with terrorism. Visual Communication Quarterly, 13(1), 4-15. 
18. Fahmy, S., Kelly, J. D., \& Kim, Y. S. (2007). What Katrina Revealed: A Visual Analysis of the Hurricane Coverage by News Wires and US Newspapers. Journalism \& Mass Communication Quarterly, 84(3), 546-561.

19. Faux II, W. V., \& Kim, H. (2006). Visual representation of the victims of Hurricane Katrina: A dialectical approach to content analysis and discourse. Space \& Culture, $9(1), 55-59$.

20. Ferguson, S. D. (2001). Researching the Public Opinion Environment. Thousand Oaks, California: Sage Publications.

21. Foss, S. (2005). Theory of visual rhetoric. In Smith, K., Moriarty, S., Barbatsis, G. \& Kenney, K. (Eds.), Handbook of visual communication: Theory, methods, and media (141-152). Mahwah, NJ: Erlbaum.

22. Garcia, M. R., \& Stark, P. (1991). Eyes on the news. St. Petersburg, FL: Poynter Institute.

23. Gefter, P. (2006, March 21). History's first draft looks much better with pictures. New York Times, p. 26.

24. Geise, S. (2017). Visual Framing. The International Encyclopedia of Media Effects, 112.

25. Geske, J., \& Brown, P. (2008, May). Gay marriage in Iowa: The visual framing of a controversial social issue. Paper presented at the annual meeting of the International Communication Association, Montreal, Canada.

26. Gibson, R. \& Zillmann, D. (2000). Reading between photographs: The influence of incidental pictorial information on issue perception. Journalism \& Mass Communication Quartely, 77(2), 355-366. 
27. Goldberg, V. (1991). The Power of Photography: How Photographs Changed our Lives. New York, NY: Abbeville Press.

28. Greenwood, K. (2012). Picturing defiance: Visions of democracy in Iran. The International Communication Gazette, 74(7), 619-635.

29. Grimes, T. \& Drechsel, R. (1996). Word-picture juxtaposition, schemata, and defamation in television news. Journalism \& Mass Communication Quarterly, 73(1), 169-180.

30. Grimes, T. (1990). Encoding TV news messages into memory. Journalism Quarterly, 67(4), 757-766.

31. Grundberg, A. (1990, August 12). Ask it no questions: The camera can lie. The New York Times, Sec. 2, p. 1.

32. Hansen, A., \& Machin, D. (2013). Researching visual environmental communication. Environmental Communication, 7(2), 151-168.

33. Harris, C. R. (1991). Digitisation and manipulation of news photographs. Journal of Mass Media Ethics, 6(3), 164-174.

34. Iyer, A., \& Oldmeadow, J. (2006). Picture this: Emotional and political responses to photographs of the Kenneth Bigley kidnapping. European Journal of Social Psychology, 36, 635-47.

35. Jackson, J. H. (2011). Envisioning disaster in the 1910 Paris flood. Journal of Urban History, 37(2), 176-207.

36. Jewitt, C. \& Oyama, R. (2001). Visual meaning: A social semiotic approach. In Leeuwen, T.V., \& Jewitt, C. (Eds.), Handbook of Visual Analysis. London: Sage, pp. 134-156. 
37. Joffe, H. (2008). The power of visual material: Persuasion, emotion and identification. Diogenes, 55, 84-93.

38. King, C., \& Lester, P. M. (2005, Autumn). Photographic coverage during the Persian Gulf and the Iraqi wars in three U.S. newspapers. Journalism and Mass Communication Quarterly, 82(3), 623-637.

39. Kiousis, S. (2004). Explicating Media Salience: A Factor Analysis of New York Times Issue Coverage During the 2000 U.S. Presidential Election. Journal of Communication, 54(1), 71-87.

40. Kolers, P. A. \& Brison, S. J. (1984). Commentary: On pictures, words, and their mental representation. Journal of Verbal Learning and Verbal Behavior, 23(1), 105-113.

41. Kress, G., \& van Leeuwen, T. (2006). Reading Images. The Grammar of Visual Design. London, New York: Routledge.

42. Kruif, J. D. (2009). Death shall have no dominion. Imaging flood disasters in the press. In A. Peto \& K. Schrijvers (Eds.), Faces of Death. Visualising history (pp. 91-121). Pisa: Pisa University Press.

43. Lester, P. M. (1991). Photojournalism: An Ethical Approach. Hillsdale, NJ: Lawrence Erlbaum Associates.

44. Lester, P. M. (2005). Visual Communication. Images with Messages. Belmont: Wadsworth.

45. Lester, P. M., \& Ross, S. D. (2003). Images that Injure: Pictorial Stereotypes in the Media ( $2^{\text {nd }}$ ed.). Westport, CT: Praeger Publishers. 
46. Matthes, J. (2009). What's in a frame? A content analysis of media framing studies in the world's leading communication journals, 1990-2005. Journalism \& Mass Communication Quarterly, 86(2), 349-367.

47. McComas, K., \& Shanahan, J. (1999). Telling stories about global climate change: Measuring the impact of narratives on issue cycles. Communication Research, 26(1), $30-57$.

48. McIntyre, J. (2010, September 10). The breakfast test. The Baltimore Sun). Retrieved from https://www.baltimoresun.com/bs-mtblog-2010-09-the breakfast test-story.html

49. Messaris, P., \& Abraham, L. (2001): The role of images in framing news stories. In S. D. Reese, O. H. Gandy \& A. E. Grant (Eds.), Framing public life: perspectives on media and our understanding of the social world (pp. 215-226). Mahwah, NJ: Erlbaum.

50. Miller, S. (1975). The content of news photos: Women's and men's roles. Journalism Quarterly, 52(1), 70-75.

51. Mirzoeff, N. (1999). Visual Culture. New York, NY: Longman.

52. Nurmis, J. M. (2017). Can photojournalism enhance public engagement with climate change? (Doctoral dissertation). Retrieved from ProQuest. (10271140)

53. O’Neill, S. J., \& Boykoff, M. (2011). The role of new media in engaging individuals with climate change. In Whitmarsh, L., O’Neill, S. J., Lorenzoni, I. (Eds.), Engaging the Public with Climate Change: Communication and Behaviour Change (pp. 233251). London: Earthscan.

54. Paivio, A. (1971). Imagery and verbal processes. New York: Holt, Rinehart, \& Winston. 
55. Paivio, A. (1986). Mental representations: A dual-coding approach. New York: Oxford University Press.

56. Paivio, A., \& Csapo, K. (1973). Picture superiority in free recall: Imagery or dual coding? Cognitive Psychology, 5, 176-206.

57. Parry, K. (2010). A visual framing analysis of British press photography during the 2006 Israel-Lebanon conflict. Media, War \& Conflict, 3(1), 67-85

58. Peirce, C. S. (1868). On a new list of categories. Proceedings of the American Academy of Arts and Sciences, 7(1868), 287-298.

59. Perlmutter, D. (1998). Photojournalism and foreign policy: Icons of outrage in international crises. Westport, CT: Praegar.

60. Perlmutter, D., \& Wagner, G. L. (2004). The anatomy of a photojournalistic icon: Marginalization of dissent in the selection and framing of 'a death in Genoa'. Visual Communication, 3(1), 91-108.

61. Popp, R. K., \& Mendelson, A. L. (2010). 'X'-ing out enemies: Time magazine, visual discourse, and the war in Iraq. Journalism, 11(2), 203-221.

62. Potter, W. J., \& Smith, S. (2000). The context of graphic portrayals of television violence. Journal of Broadcasting \& Electronic Media, 44(2), 301-323.

63. Quinn, A., \& Spence, E. (2004). Manipulation in photojournalism: Is it ethical? Is it corrupt? In A. Dunn (Ed.), Australia-New Zealand Communication Association Conference 2004 Proceedings (pp. 1-15). Sydney, Australia: University of Sydney.

64. Rebich-Hespanha, S., Rice, R. E., Montello, D. R., Retzloff, S., Tien, S. \& Hespanha, J. P. (2015). Image Themes and Frames in US Print News Stories about Climate Change. Environmental Communication, 9(4), 491-519. 
65. Rivers, W. L., \& Matthews, C. (1988). Ethics for the media. Englewood Cliffs, JN: Prentice Hall.

66. Rodgers, S., \& Thorson, E. (2000). The Interactive Advertising Model: How Users Perceive and Process Online Ads. Journal of Interactive Advertising, 1(1), 42-61.

67. Rodgers, S., Kenix, L. J., \& Thorson, E. (2007). Stereotypical portrayals of emotionality in news photos. Mass Communication \& Society, 10(1), 119-138.

68. Rodriguez, L., \& Dimitrova, D. V. (2011). The levels of visual framing. Journal of Visual Literacy, 30(1), 48-65.

69. Rosen, C. (2005). The Image Culture. The New Atlantis: A Journal of Technology and Society, 10, 27-46.

70. Schwalbe, C. B. (2006). Remembering our shared past: Visually framing the Iraq war on U.S. news websites. Journal of Computer-Mediated Communication, 12, 264-289.

71. Seelig, M. (2005). A case for the visual elite. Visual Communication Quarterly, 12(34), 164-181.

72. Severin, W. J. (1967). Pictures as relevant cues in multi-channel communication. Journalism Quarterly, 44(1), 17-22.

73. Sharkey, J. (1993). When pictures drive foreign policy: Somalia raises serious questions about media influence. American Journalism Review, 15(10), 14-19.

74. Sontag, S. (2003). Regarding the Pain of Others. London: Penguin.

75. Tewksbury, D. and Scheufele. D. A. (2009). News framing theory and research. In J. Bryant, \& M. B. Oliver (Eds.), Media effects: Advances in theory and research, (pp. 17-33). New York: Routledge. 
76. Vliegenthart, R. (2012). Framing in Mass Communication Research - An Overview and Assessment. Sociology Compass, 6(12), 937-948.

77. Wanta, W. (1988). The Effects of Dominant Photographs: An Agenda-Setting Experiment. Journalism Quarterly, 65(1), 107-111.

78. Wanta, W., \& Roark, V. (1993, August). Cognitive and affective responses to newspaper photographs. Paper presented to the Visual Communication Division at the Association for Education in Journalism and Mass Communication annual conference, Kansas City, MO.

79. Wedel, M., \& Pieters, R. (2007). Visual Marketing. From Attention to Action. New York, Oxford: Psychology Press.

80. Wischmann, L. (1987). Dying on the front page: Kent State and the Pulitzer Prize. Journal of Mass Media Ethics, 2(2), 67-74.

81. Zillmann, D., Gibson, R., \& Sargent, S. L. (1999). Effects of Photographs in NewsMagazine Reports on issue Perception. Media Psychology, 1(3), 207-228. DOI: 10.1207/s1532785xmep0103_2 